\title{
Working Memory Capacity Predicts Individual Differences in Social Distancing Compliance during the COVID-19 Pandemic in the U.S.
}

Weizhen Xie ${ }^{* 1}$, Stephen Campbell ${ }^{2}$, Weiwei Zhang ${ }^{2}$

1. National Institute of Neurological Disorders and Stroke, National Institutes of Health

2. Department of Psychology, University of California, Riverside

${ }^{*}$ Corresponding author: Weizhen Xie

Email: weizhen.xie@nih.gov

OCRID: 0000-0003-4655-6496

\section{Classification}

Social Science: Psychological and Cognitive Sciences

\section{Keywords}

Working Memory, Social Distancing, Social Norm, Individual Differences, COVID-19

\section{Author Contributions}

W. Xie developed the research framework, collected data, and performed analyses with assistance from S. Campbell. W. Xie and W. Zhang contributed to study design and manuscript preparation.

This PDF file includes:

Main Text

Figures 1 to 2

Tables 1 to 2

Supplementary Information 


\begin{abstract}
Noncompliance with social distancing during the early stage of the COVID-19 pandemic poses a great challenge to the public health system. These noncompliance behaviors partly reflect people's concerns for the inherent costs of social distancing while discounting its public health benefits. We propose that this oversight may be associated with the limitation in one's mental capacity to simultaneously retain multiple pieces of information in working memory (WM) for rational decision making that leads to social distancing compliance. We tested this hypothesis in 850 U.S. residents during the first 2 weeks following the presidential declaration of national emergency because of the COVID-19 pandemic. We found that participants' social distancing compliance at this initial stage could be predicted by individual differences in WM capacity, partly due to increased awareness of benefits over costs of social distancing among higher WM capacity individuals. Critically, the unique contribution of WM capacity to the individual differences in social distancing compliance could not be explained by other psychological and socioeconomic factors (e.g., moods, personality, education, and income levels). Furthermore, the critical role of WM capacity in social distancing compliance can be generalized to the compliance with another set of rules for social interactions, namely the fairness norm, in Western cultures. Collectively, our data reveal novel contributions of a core cognitive process underlying social distancing compliance during the early stage of the COVID-19 pandemic, highlighting a potential cognitive venue for developing strategies to mitigate a public health crisis.
\end{abstract}

\title{
Significance Statement
}

Before vaccination and other intervention measures become available, successful containment of an unknown infectious disease critically relies on people's voluntary compliance with the recommended social distancing guidelines. This involves a decision process of prioritizing the merits of social distancing over its costs, which may depend on one's ability to compare multiple pieces of potentially conflicting information regarding social distancing in working memory (WM). Our data support this hypothesis, highlighting the critical role of one's WM capacity in social distancing compliance during the early stage of the COVID-19 pandemic. This novel observation reveals a core cognitive limitation in one's response to a public health crisis and suggests a possible cognitive venue for the development of strategies to mitigate such a challenge. 


\section{Introduction}

The rapid outbreak of the novel coronavirus, COVID-19, poses a great challenge to almost every aspect of our everyday life. Because this virus can rapidly spread from person to person (1), restricting close-distance human interactions, also known as social distancing, is an effective measure to contain its transmission (2) and to prevent straining public health resources $(3,4)$. This measure mandates behaviors such as avoiding congregate settings and mass gathering, maintaining distance from others, and self-isolation (5). Before vaccination and other interventions become available, these behaviors will remain critical for an extended period of time, even after the government's stay-home and shelter-in-place orders are lifted. However, in a society where social distancing mostly remains voluntary, there is wide spread noncompliance, especially during the early stage of this pandemic $(6,7)$. This may be partly due to the concerns for the inherent costs associated with social distancing. Informed decision weighting benefits over costs is thus a critical mental process underlying social distancing compliance (8). However, what constitutes an individual's cognitive ability to formulate such a decision remains largely unclear.

This study thus aims to investigate whether and how a core cognitive function, namely working memory (WM), is associated with individual differences in social distancing compliance during the early stage of the COVID-19 pandemic. WM retains a limited amount of information over a short time period at the service of other ongoing mental activities. Its limited capacity constrains our mental functions (9-11), such that higher WM capacity is often associated with better cognitive and affective outcomes (12-15). For example, higher WM capacity supports better learning in face of the adverse influences from stress (16). It also allows better cost-and-benefit evaluation of a given action under uncertainty (17), which can lead to better decisions $(18,19)$. Once a decision is made or a new rule is set, higher WM capacity is further associated with a better ability to retain and follow the decision or rule (20-22). Given these critical roles of WM, we hypothesize that individuals with higher WM capacity may better understand the true merits of social distancing despite its potential costs, and subsequently show more compliance with recommended social distancing guidelines during the early stage of the COVID-19 outbreak.

Our hypothesis echoes with the theoretical emphasis on cognitive variables (e.g., reinforcement learning) in an individual's choice to follow a set of well-established rules for social interactions, often referred to as social norms (23-25). This cognitive approach is complementary to previous research on various social and affective factors underlying social norm compliance (26). For example, individuals who have certain personality traits (e.g., considerateness) or feel anxious about pursuing social acceptance often show more social norm compliance (27-30). However, different from plenty of opportunities for reinforced learning of well-established social norms $(23,25)$, compliance with a still developing norm of social distancing during the early outbreak of an unknown infectious disease poses a unique demand on one's ability to rapidly carry out deliberate cost-and-benefit analysis (8). It remains unclear whether WM plays a unique role in this type of decision, especially after taking into account other social and affective factors, such as personality and anxious feelings (26-31). Identification of the essential cognitive building blocks underlying this decision process may pave the road for developing strategies $(32,33)$ to reduce social distancing noncompliance for mitigating a public health crisis (34).

We test our hypothesis in two studies with a diverse group of 850 U.S. participants (see Supplementary Table S1) from the online Amazon Mechanical Turk (mTurk) experimental platform. These studies were conducted within the first two weeks (March 13 to 26, 2020) following the U.S. federal government's declaration of national emergency due to the COVID-19 pandemic. During this period, social distancing progressively developed into a norm. Several states have issued stay-at-home orders. Still, many people failed to follow these guidelines (6). Study 1 examined these individual differences by asking participants to report their social distancing compliance levels. Participants also completed a change localization task as a task measure of WM capacity (see Figure $1 \mathrm{~A}$ ) and a package of questionnaires capturing mood-related conditions during this period, including depressed mood, anxious feelings, and sleep quality (31). We found that WM capacity significantly predicted individual differences in social distancing compliance even after taking into account other mood-related covariates. Study 2 replicated findings from Study 1 , and further factored out the contributions of several personality variables and fluid intelligence in the observed relationship between WM capacity and social distancing compliance. Furthermore, we found that participants' understanding of the merits of social distancing 
mediated the relationship between WM capacity and social distancing compliance. Finally, we generalized the main findings from social distancing compliance to the compliance of another social norm, namely the fairness norm, in Western cultures (35). Collectively, our data highlight the critical role of WM capacity in social cognition and behavior (33) .

\section{Results}

\section{Measure of Social Distancing Compliance and its Relationship with Other Variables of Interest}

Across two studies, two independent groups of mTurk participants reported how closely they had followed a set of practices to keep away from close-distance social interactions in the past week (e.g., whether they have canceled social gathering with friends and avoided handshakes, hugs, or kisses when greeting, see Materials and Methods for details). To estimate the validity of this measure, we correlated participants' total scores for social distancing compliance with their self-report numbers of times that they had left their home and with the frequency of hand washing in the past week, using Spearman rank-order correlations. Our assumption is that participants who are more likely to comply with social distancing guidelines are less likely to leave their home and are more cognizant about the means to prevent disease transmission. Indeed, we found that participants with higher scores in social distancing compliance also reported leaving home less $(\rho=-.32[-.40,-.22], p<.001, n=397$ in Study 1 and $\rho=-.19$ [-.28, -.10], $p$ $<.001, n=453$ in Study 2$)$, but washing hands more frequently $(\rho=.54[.46, .60], p<.001$ in Study 1 and $\rho=.34[.25, .42], p<.001$ in Study 2). In contrast, this social distancing compliance measure was not significantly correlated with education or income levels of the participants, even though female and older participants tended to show more social distancing compliance (see Supplementary Table S2 and S3).

Of primary interest, we found that social distancing compliance was significantly correlated with participants' ability to retain a certain number of color squares in WM, namely WM capacity, measured from an established change localization task $(36,37)$. In this task, on each trial, participants tried to remember a set of briefly presented color squares over a short delay and reported a changed color in a second set of color squares, by clicking on the changed color (Figure 1A). Response accuracy across trials was converted to $\mathrm{K}(38)$, as the task measure of the total number of remembered items (i.e., WM capacity). We found that higher visual WM capacity was significantly correlated with more social distancing compliance both in Study $1(r=.29$ [.20, .38], $p<.001)$ and in Study $2(r=.25$ [.17, .34], $p$ $<.001$ ). In addition, individuals with higher WM capacity who scored above the median $\mathrm{K}$ value in each sample indeed reported more social distancing compliance (Figure 1B), as compared with lower WM individuals (Study1: $t_{(395)}=4.72, p<.001$, Cohen's $d=0.47$ [0.27, 0.67]; Study 2: $t_{(451)}=3.97, p<.001$, Cohen's $d=0.37[0.19,0.56])$. We also found that social distancing compliance and K were significantly correlated with other affective and trait variables, such as depressed mood, anxious feelings, agreeableness, and fluid intelligence (Supplementary Table S2 and S3). The critical issue then is whether the association between WM capacity and social compliance distancing can be accounted for by these mood-related and trait-related covariates. To address this issue, we adopted a regression approach to investigate the unique variance in social distancing compliance explained by WM capacity after taking into account other covariates (39-41).

\section{WM Capacity Contributes Unique Variance to Social Distancing Compliance}

In Study 1, we first looked at whether WM capacity could predict social distancing compliance after taking into account several mood-related covariates, such as depressed mood, anxious feelings, and poor sleep quality (see Materials and Methods for details). These variables have all been previously linked to reduced WM capacity (42-44), and our current data replicated these previous observations (Supplementary Table S2 and S3). Nonetheless, we found that WM capacity remained a robust predictor of social distancing compliance $(\beta=.18[.09, .28], p<.001)$, even after taking into account these moodrelated covariates and other demographic variables, including age, gender, education, and income levels. This observation remained robust when WM capacity was entered into the regression model as the last 
predictor $\left(\Delta \mathrm{R}^{2}=.03, F_{(1,388)}=13.57, p<.001\right)$, suggesting that WM capacity contributed unique and additional variance to individual differences in social distancing compliance (see Table 1).

In Study 2, we further evaluated the robustness of this observation after factoring out some additional covariates, such as the "big five" personality and fluid intelligence. Although individuals with certain personality types showed more social distancing compliance (e.g., agreeableness, $\beta=.18$ $[.08, .27], p<.001)$, consistent with some previous findings regarding personality and social norms (27), it did not take away the unique contribution of WM capacity to social distancing compliance. Likewise, although fluid intelligence was a significant predictor of social distancing compliance $(\beta=.13[.05, .22], p$ $=.003)$, its contribution attenuated $(\beta=.09[-.005, .18], p=.063)$ when WM capacity was entered into the model as the last predictor. These observations were supported by a model comparison between the regression models with and without WM capacity as an additional predictor $\left(\beta=.14[.05, .24], \Delta \mathrm{R}^{2}=.02\right.$, $F_{(1,439)}=8.50, p=.004$, see Table 2). Altogether, converging findings from Study 1 and 2 indicate the unique and significant contribution of WM capacity to individual variations in social distancing compliance, which cannot be simply accounted for by mood-related variables, personality, or fluid intelligence of the participants.

\section{Weighting Benefits over Costs Mediates the Relationship between WM Capacity and Social Distancing Compliance.}

We next examined how WM capacity might account for unique variance in social distancing compliance. Our working hypothesis is that higher WM capacity may facilitate one's ability to perform cost-and-benefit analysis of social distancing practice, which subsequently facilitates social distancing compliance. This hypothesis predicts that participants' understanding about benefits over costs of social distancing mediates the relationship between WM capacity and social distancing compliance. We tested this prediction in Study 2, in which participants evaluated the extent to which they agreed with several statements regarding social distancing during the COVID-19 pandemic (see Materials and Methods, as well as Supplementary Table S4). Some of these items highlight the needs or benefits to perform social distancing (e.g., "social distancing may minimize the burden on medical resources, so people in need can use them"), whereas others highlight the potential costs associated with social distancing (e.g., "small business could not survive if people keep social distancing"). We standardized the sum scores for the benefit- and cost-related items separately and then calculated the difference score as a measure of participants' understanding of benefits over costs regarding social distancing at the time of testing.

We subsequently performed a formal mediation analysis (45), using WM capacity as a predictor, social distancing compliance as the outcome variable, and participants' understanding of benefits over costs about social distancing as a mediator (see Figure 1C). After factoring out other covariates as the background confounders (see Materials and Methods), we found that participants' understanding of benefits over costs significantly mediated the relationship between WM capacity and social distancing (indirect effect: $\beta=.03[.003, .07], p=.038$ ). However, it was a partial mediation effect since this mediator did not fully take away the direct contribution of WM capacity to social distancing compliance $(\beta=.11$ $[.02, .21], p=.013)$.

\section{WM Capacity also Predicts the Compliance of Fairness Norm}

To understand the more general role of WM capacity in social norm compliance, we asked participants in Study 2 to perform an additional social norm decision-making task (Figure 2A and 2B), which involved staged interactions between two anonymous players with real financial consequences (35, 46). At the beginning of this task, participants were told that they would be randomly paired with another mTurk worker and that they could be arbitrarily assigned into different roles ("Player A" vs. "Player B"). In fact, all participants were assigned to be "Player A", whereas "Player B" was simulated by a preprogramed algorithm (46). The two players began each round with 25 money units (MUs), but Player $\mathrm{A}$ (the participant) received an additional $100 \mathrm{MUs}$ and could decide to transfer $\mathrm{X}$ amount of MUs deemed fair by himself/herself to Player B (baseline condition). In another condition, Player B could respond to the 
MU transfer by either accepting it if it was fair or punishing Player A by $Y$ amount of MUs if it was deemed unfair (punishment condition). We simulated the amount of punishment based on the probability distribution and magnitude of how a real human Player B would have responded in this task from previous studies $(33,41$; also see Supplementary Table S5).

According to the fairness norm in Western cultures, the ultimate fairness in this social setting would be an even split of the MUs between the two players (i.e., "split the cake"). However, this would conflict with Player A's self interest in obtaining more MUs for a higher monetary reward, and consequently Player A generally tended to transfer a smaller amount of MUs to Play B in the baseline condition. In contrast, when a sanctioning threat was present as a reminder to comply with the fairness norm in the punishment condition, Player A tended to transfer more MUs to Player B $(35,46)$. We replicated these observations from previous research. Specifically, the amount of MUs the participants as Player A transferred to Player B was statistically not different from the fairness norm (i.e., 50 Mus) in the punishment condition $\left(t_{(452)}=1.13, p=.26\right.$, Cohen's $d=0.05[-0.04,0.15]$, Bays Factor in favor of the null hypothesis $=10.02$ ). In contrast, participants as Player A transferred significantly fewer MUs to Player B in the baseline relative to the punishment condition $\left(t_{(452)}=11.59, p<.001\right.$, Cohen's $d=0.55[0.45,0.64]$, also see Figure $2 \mathrm{C}$ ). Consequently, the difference in the amount of transferred MUs between punishment and baseline conditions could capture individual differences in sanction-induced fairness norm compliance by taking into account individual differences in altruism and response biases (35).

We next evaluated whether WM capacity had a unique contribution to individual differences in sanction-induced fairness norm compliance. We found that WM capacity was significantly correlated with participants' compliance with the fairness norm ( $r=.26[.17, .34], p<.001$, Figure 2D). Furthermore, WM capacity's contribution to individual differences in fairness norm compliance $\left(\beta=.10[.003, .20], \Delta R^{2}=.01\right.$, $\left.F_{(1,439)}=4.13, p=.043\right)$ could not be accounted for by other significant predictors of performance in this task (see Supplementary Table S6), such as continuousness $(\beta=.13[.02, .24], p=.018)$ and fluid intelligence $(\beta=.26[.16, .35], p<.001)$. This may be because that individuals with higher WM capacity can better evaluate the consequences of not following the fairness norm, such that they can maximize the total amount of reward in the end. This prediction was supported by a significant correlation between WM capacity and total amount of earned MUs across participants $(r=.28[.20, .37], p<.001)$. Furthermore, participants' compliance to the fairness norm was significantly correlated with social distancing compliance as well $(r=.18[.09, .27], p<.001)$. Altogether, these results suggest that participants who are more inclined to follow one set of social norms may also be more likely to follow another set of social norms, which are both highly related with individual differences in WM capacity.

\section{Discussion}

This study reveals a novel cognitive root of social distancing compliance during the early stage of the COVID-19 pandemic. We find that WM capacity contributes unique variance to individual differences in social distancing compliance, which may be partially attributed to the relationship between WM capacity and one's ability to evaluate the true merits of the recommended social distancing guidelines. This association remains robust after taking into account individual differences in age, gender, education, socioeconomic status, personality, mood-related conditions, and fluid intelligence. This unique contribution of WM capacity can also be generalized to fairness norm compliance, suggesting a critical role of WM capacity in social cognition and behavior (33). Altogether, this study adds novel insights into the cognitive building blocks that may lead to better social distancing compliance.

Of paramount interest, our findings are in line with the theoretical framework that social distancing compliance during the early outbreak of an infectious disease is driven by deliberate thoughts about the costs and benefits of this practice (8). Our novel observation is that the decision to follow the social distancing norm in prioritizing societal benefits over personal costs is contingent on one's WM capacity, the core of human cognition (9). Critically, this does not seem to a special case of WM's contributions to a specific social behavior, because WM capacity can also predict fairness norm compliance. These unique contributions of WM capacity to social norm compliance cannot be accounted for by other wellacknowledged factors, such as an individual's moods (31), personality traits, fluid intelligence, or 
socioeconomic status (e.g., education and income levels). These robust findings add to the growing literature on the importance of cognitive factors in social norm compliance $(23,25)$. Furthermore, in response to a recent call of applying behavioral science principles to mitigate the COVID-19 pandemic ( 7 , 34,47 ), our results suggest a possible cognitive venue for developing strategies meet this challenge.

These behavioral associations may be driven by shared neurocognitive mechanisms underlying WM capacity and social norm compliance in the prefrontal regions $(35,46)$. On the one hand, WM capacity is closely related to prefrontal mental processes, such as decision making, cognitive control, and fluid intelligence in healthy and clinical populations (48-52). On the other hand, social norm compliance has also been attributed to the prefrontal cortex (46), such that transcranial electrical stimulation over the prefrontal cortex can improve social norm compliance (35). By bridging these two parallel lines of research, our data provide preliminary support for the potentials of intervention strategies targeting prefrontal functions (e.g., WM training) in mitigating social norm noncompliance $(53,54)$.

Some caveats should be noted in this study. First, given the theoretical roles of attention in WM $(9,55)$, the observed relationships between WM capacity and social distancing compliance may result from individual differences in our ability to control contents of attention especially when confronted with conflicting information $(55,56)$. Future research needs to systematically assess the contributions of other cognitive factors, such as attention control, in social norm compliance. Second, this study investigates social distancing compliance in a society when social distancing has remained largely voluntary and people could make different choices $(7,8)$. However, when social distancing is mandatory, compliance may be more related with other factors, such as the concerns about legal violations and the anxiety associated with being infected by the virus (31). Third, social norm compliance was assessed using selfreport measure. Although this measure correlated with other practice for reducing the risk of getting infected (e.g., more home stay and frequent hand washing), it could reflect participants' attitude more than their own behaviors regarding social distancing. That said, as attitude and behaviors are highly correlated (57), changes in attitude may be accompanied by corresponding behavioral changes over time (58). Last, the present observations are correlational in nature. Thus, the casual inference regarding the relationship between WM capacity and social distancing compliance needs to be tested in future studies, such as by using WM training (33) or non-invasive brain stimulation (35).

In conclusion, the current study reveals a novel behavioral association between WM capacity and social distancing compliance, partially mediated by cost-and-benefit analysis of social distancing practice, during the early stage of the COVID-19 pandemic in the U.S. This critical role of WM capacity in social distancing can be generalized to another social norm, such as the fairness norm in Western cultures. These novel findings provide a potential cognitive venue for the development of strategies to mitigate social distancing noncompliance in a public health crisis. 


\section{Materials and Methods}

\section{Participants}

Across the two experiments, 1159 participants (552 females; $38.51 \pm 12.39$ [mean \pm SD] years old) were recruited from the online Amazon Mechanical Turk (mTurk) experimental platform. The study was only accessible to participants with an IP address located within the U.S. Only participants who met these following inclusion criteria were included for further analyses, resulting in a final sample size of 850 participants (410 females; $38.24 \pm 11.98$ years old). Specifically, all eligible subjects 1 ) finished the study within more than $8 \mathrm{~min}$ (minimal time for just clicking through the survey and tasks), 2) responded accurately in a "trap question" (59) that was presented intermixed with other survey items (see Supplementary Information for an example), and 3) performed above-chance in the change localization task performance ( $20 \%$ as the chance performance for set size 5 , see Procedure for details). In Study 2 , we additionally excluded participants with unmeaningfully fast responses for more than one-third of the trials in the Raven's Advanced Progressive Matrices task, to ensure a reliable measure of fluid intelligence. The unmeaningfully fast responses were defined as the trials with response time less than half a second, considering that mean response time was $18.92 \pm 19.40$ seconds for each question regardless of accuracy in the Raven's Advanced Progressive Matrices task. These criteria were implemented mainly for controlling data quality (60). Consequently, 397 (198 females; $39.08 \pm 12.37$ years old) out of 525 participants recruited between March 20 and 22, 2020 in Study 1 and 453 (241 females; $37.51 \pm 11.58$ years old) out of 634 total participants recruited between March 24 and 26, 2020 in Study 2 met these criteria. Note, the exclusion percentage is on a par with other cognitive studies using mTurk (61). Further details about the demographic information about these participants can be found in Supplementary Table S1. No statistical methods were used to pre-determine the sample sizes. That said, our sample sizes are similar to previous studies on individual differences, and had a reasonable statistical power $(80 \%)$ to detect a median size significant effect from regression and mediation analyses $(62,63)$.

Informed consent was obtained prior to the study following the protocol approved by the Institutional Review Board (IRB) of the University of California, Riverside. In brief, before participants decided to continue on the study by clicking a "proceed" button on the webpage, they were presented with detailed information including the purposes, procedures, potential risks/benefits, confidentiality, and compensation of the study. All participants were informed that they could withdraw from the study at any time by closing the web browser and still get compensated for their time in the study. Non-identifiable data from all 1159 participants with analytical scripts/files are available at the Open Science Framework data repository (https://osf.io/uhns4/).

\section{Procedure}

Participants at first completed a demographic survey, which included age, gender, ethnicity, education, and income level relative to their respective age group. Afterwards, participants in Study 1 completed a visual WM change localization task and a set of questionnaires, capturing individual differences in social distancing compliance, depressed mood, anxious feelings, and sleep quality. Participants in Study 2 completed similar tasks and questionnaires with these following exceptions. First, we included additional measures of personality variables and fluid intelligence. Second, we included more questions capturing participants' understanding about the costs and benefits of social distancing practice. Third, we also included an additional decision masking task that assessed individual differences in fairness norm compliance. Finally, we dropped the sleep quality measure to save time. Both studies were programmed using PsyToolkit $(64,65)$. Further details of these measures are described below.

\section{Study 1}

Visual WM Change Localization Task. In this task, observers saw a set of 5 color squares (70 by 70 pixels each) presented on a computer screen ( 800 by 600 pixels through a webpage browser) for $500 \mathrm{~ms}$ and tried to remember them as best as they can. After a 1000-ms delay period with a blank screen, participants saw another set of squares with repeated colors, except for one square, from the initial study set. Observers were asked to use a computer mouse to click on the color square that differed 
from its initial color (see Figure 1A). Colors used in this task were randomly sampled from a set of 8 perceptually distinct colors (i.e., blue, green, red, yellow, brown, magenta, lime green, and cyan). And they were presented at 5 different locations randomly sampled from a set of 16 possible locations, in a 4 by 4 grid centering on the display screen, with 107 pixels between the centers of every two locations. Participants responded at their own pace to prioritize response accuracy over speed. Set size 5 was used to ensure that the tested set size was larger than the typical WM capacity for colors, which was about 3 to 4 in the general population $(9,11)$, and that the task was at a medium difficulty level (37). All participants completed 5 practice trials, followed by 20 experimental trials. Participants' performance in this task was measured as K [(proportion correct $\times$ set size $)-1]$ for the number of items held in visual WM (42), which is a reliable and valid estimate of visual WM capacity $(36,38)$. Using this measure from online participants in the current study, we were able to replicate some previous findings $(42-44,66)$ from college students in more controlled laboratory settings. For example, we replicated the findings that reduced WM capacity was associated with self-report measures of depressed mood $(r=-.37[-.45,-.28], p<.001)$, anxious feelings $(r=-.26[-.35,-.17], p<.001)$, and poor sleep quality $(r=-.24[-.33,-.14], p<.001)$.

Social distancing compliance. In this self-report questionnaire, we asked participants to report how closely they followed a set of social distancing practice in the past week (from "Do not consider following" = 0 to "Follow very frequently" = 3). These items include whether a participant has "held no social gathering with friends", "cancelled events or plans to go to an event," "stopped going to the church or attending other community activity," and "had no handshakes, hugs, or kisses when greeting." We combined participants' responses from these questions to formulate a composite score of social distancing compliance (Cronbach's $\alpha=.83$ ). To estimate the validity of these measures, in separate questions, we further asked participants to report the number of times they had left their home in the past week and how frequently they had washed their hands in the past week on a 4-point scale.

Depressed mood. We used the Patient Health Questionnaire-9 (PHQ-9) to measure participants' depressed feelings within the past week (67). Participants indicated how often in the past week they have been bothered by one of the 9 symptoms using a 4-point scale (from "Not at all $=0$ " to "Nearly Every Day $=3$ "). Possible scores range from 0-27, with 0 indicating no experience of depressed mood and 27 reflecting severe depression (Cronbach's $\alpha=.94$ ).

Anxious Feelings. We used the Generalized Anxiety Disorder-7 (GAD-7) scale to capture participants' overall anxious feelings about an uncertain situation (68). Participants respond to 7 symptom questions by indicating how often in the past week they have been bothered by that symptom using a 4point scale (from "Not at all = 0" to "Nearly Every Day = 3"). Possible scores range from 0-21, with a higher score indicating more anxious feelings (Cronbach's $\alpha=.94$ ).

Sleep Quality. Pittsburgh Sleep Quality Index (PSQI) was used to assess participants' sleep quality over last week (69). The full index ranges from 0 to 21, with higher scores indicating poorer sleep quality. This scale has a reasonable internal reliability with a Cronbach's $\alpha$ as .60 in the current sample. Higher PSQI scores have been reliably shown to be correlated with lower visual WM capacity (44).

\section{Study 2}

Understanding of Benefits and Costs about Social Distancing. We collected a set of statements based on news reports and opinions from medical experts (see Supplementary Table S2), and asked participants to report the extent to which they think these statements were true on a 4-point scale ("Don't think it is true" $=0$ to "It is very true" $=3$ ). These statements can be categorized into benefitrelated and cost-related items. We calculated the sum scores within each category, and then standardized them separately before taking the difference between the benefit-related and cost-related scores. This composite score provides an estimate about participants' attitude towards the benefits over costs regarding social distancing practice. The internal consistency measure of Cronbach's $\alpha$ of the full scale is .61, and a principle component analysis further support two separable components in participants' responses (see Supplementary Table S2). 
Fairness Norm Compliance Task. This task was modified from the ultimatum game in previous studies to assess fairness norm compliance $(35,46)$. We simplified this task to optimize behavioral performance for the online data collection environment. In this paradigm, participants repeatedly took the role of Player $A$ and were told that they were randomly paired in every round with another mTurk worker as Player B. In every round both players would receive an initial endowment of 25 money units (MUs). Player A would additionally receive $100 \mathrm{MUs}$, totaling the endowment of $125 \mathrm{MUs}$ in each round. Player A was given the options to share $X$ amount of MUs to Player $B$, from 0 to 100 in steps of 10 . This decision was made by directly selecting a button on the screen corresponding to the number of MUs Player $A$ would like to share. Player $A$ had as much time as needed to make this decision. In baseline rounds (see Figure 2A), Player A could propose a transfer of X MUs, and Player B could only choose to accept the proposal. In this case, the transfer would be implemented as it was, reducing Player A's available MUs by $X$ MUs. In the punishment condition (see Figure 2B), by contrast, Player B had the option to accept or punish Player A by taking away $Y$ amount of MUs from Player A, which could vary from 0 to 125 MUs. This means, for example, if Player A gave nothing to Player B, Player B could reduce Player A's earning to 0 by taking away all 125 MUs from Player A. Each participant completed 8 rounds of baseline trials and another 8 rounds of the punishment trials. These two types of trials were randomly intermixed in the experiment. On average, Player A earned $1016.49( \pm 245.36)$ MUs in total. These points were converted to additional cash bonus to their Amazon account at the end of the experiment (scaled from 0 to $1.5 \mathrm{US}$ dollars for minimal to maximum amount of points). Although Player A was told to play this game with another mTurk worker, Player A was in fact interacting with a pre-programmed computer algorithm. In punishment rounds, this algorithm "punished" low transfer levels with the same probability and magnitude based on how a human partner would have responded in a real social interaction from previous studies (29, 30, also see Supplementary Table S5).

Fluid Intelligence. We used the short version of Raven's Advanced Progressive Matrices to assess one's reasoning and problem solving skill $(70,71)$, which is referred to as fluid intelligence (72). We selected one practice question from Set I (i.e., Problem 1) and 12 questions from Set II (i.e., Problems $1,4,8,11,15,18,21,23,25,30,31$, and 35 ). These problems were presented sequentially from easy to difficult. The problem and options for the answer were simultaneously presented on the computer screen via a webpage browser. Participants could take as much time as they wanted to choose an answer and were encouraged to try to correctly solve as many problems as possible. We found that participants' performance in this task were significantly correlated with visual WM capacity measure $(r=.39$ [.31, .46], $p<.001)$, which is highly consistent with what has been reported in the literature $(15,73)$.

"Big Five" Personality. To account for personality covariates associated with social distancing compliance, we included a short-form "Big Five" personality inventory (74). Participants were asked to indicate the extent to which they agree with a statement about themselves (e.g., "I see myself as someone who is relaxed, handles stress well) from "strongly disagree" to "strongly agree" on a 5-point Likert scale. We used these self-report ratings to calculate participants' scores on five pre-defined personality dimensions, which are extraversion, agreeableness, conscientiousness, neuroticism, and openness, based on the scoring guideline in a previous study (74). The correlations among "big five" components were consistent with those reported in the literature $(39,41)$.

\section{Data analysis.}

We assessed the unique variance WM capacity contributes to social distancing compliance using multiple regression. We entered WM capacity as the last predictor in the regression model, after other covariates have been taken into account (39-41). The amount of additional variance that WM capacity could explain for the outcome variable was therefore unlikely to be accounted for by other covariates. In the mediation analysis (45) for the relationship between WM capacity and social distancing compliance, we used WM capacity as the predictor, social distancing compliance as the outcome variable, and participants' understanding of benefits over costs about social distancing as the mediator. Other covariates, such as age, gender, education, income level, depressed mood, anxious feelings, personality, and fluid intelligence were treated as background confounders. We used bias-corrected bootstrapped method to estimate the direct and indirect effects (75). All $p$ values reported in this study are two-tailed. 


\section{Acknowledgement}

We thank Lawrence D. Rosenblum, Brent Hughes, Parisa Parsafar, and two anonymous reviewers for their suggestions on our study. W. Xie is a recipient of the National Institute of Neurological Disorders and Stroke Competitive Postdoctoral Fellowship Award. This study was funded by an internal bridge fund from the Department of Psychology, University of California, Riverside, awarded to W. Zhang. We are indebted to all participants who have contributed their time to participate in this study. 


\section{References}

1. US Centers for Disease Control and Prevention, How coronavirus spreads (2020).

2. M. Chinazzi, et al., The effect of travel restrictions on the spread of the 2019 novel coronavirus (COVID-19) outbreak. Science 9757, 1-12 (2020).

3. R. J. Glass, L. M. Glass, W. E. Beyeler, H. J. Min, Targeted social distancing design for pandemic influenza. Emerg. Infect. Dis. 12, 1671-1681 (2006).

4. C. Chu, J. Lee, D. H. Choi, S. K. Youn, J. K. Lee, Sensitivity Analysis of the Parameters of Korea's Pandemic Influenza Preparedness Plan. Osong Public Heal. Res. Perspect. 2, 210-215 (2011).

5. US Centers for Disease Control and Prevention, Interim US Guidance for Risk Assessment and Public Health Management of Persons with Potential Coronavirus Disease 2019 (COVID-19)

Exposures: Geographic Risk and Contacts of Laboratory-confirmed Cases (2020).

6. G. H. Sanchez, 24 Pictures Of Americans Failing Horribly At Social Distancing During The Coronavirus Outbreak. BuzzFeedNews (2020).

7. C. Betsch, How behavioural science data helps mitigate the COVID-19 crisis. Nat. Hum. Behav. 4, 438-438 (2020).

8. T. C. Reluga, Game theory of social distancing in response to an epidemic. PLoS Comput. Biol. 6, 1-9 (2010).

9. N. Cowan, The magical number 4 in short-term memory: A reconsideration of mental storage capacity. Behav. Brain Sci. 24, 87-185 (2001).

10. W. Zhang, S. J. Luck, Discrete fixed-resolution representations in visual working memory. Nature 453, 233-235 (2008).

11. S. J. Luck, E. K. Vogel, Visual working memory capacity: From psychophysics and neurobiology to individual differences. Trends Cogn. Sci. 17, 391-400 (2013).

12. C. S. Lee, D. J. Therriault, The cognitive underpinnings of creative thought: A latent variable analysis exploring the roles of intelligence and working memory in three creative thinking processes. Intelligence 41, 1-15 (2010).

13. W. Xie, et al., Affective bias in visual working memory is associated with capacity. Cogn. Emot. 31, 1345-1360 (2017).

14. J. A. Mikels, P. A. Reuter-Lorenz, Affective Working Memory: An Integrative Psychological Construct. Perspect. Psychol. Sci. 14, 543-559 (2019).

15. K. Fukuda, E. Vogel, U. Mayr, E. Awh, Quantity, not quality: The relationship between fluid intelligence and working memory capacity. Psychon. Bull. Rev. 17, 673-679 (2010).

16. A. R. Otto, C. M. Raio, A. Chiang, E. A. Phelps, N. D. Daw, Working-memory capacity protects model-based learning from stress. Proc. Natl. Acad. Sci. 110, 20941-20946 (2013).

17. A. Czernatowicz-Kukuczka, K. Jaśko, M. Kossowska, Need for closure and dealing with uncertainty in decision making context: The role of the behavioral inhibition system and working memory capacity. Pers. Individ. Dif. 70, 126-130 (2014).

18. V. Bagneux, N. Thomassin, C. Gonthier, J. L. Roulin, Working memory in the processing of the lowa Gambling Task: An individual differences approach. PLoS One 8, 1-6 (2013).

19. J. F. Cui, et al., Effects of working memory load on uncertain decision-making: Evidence from the lowa Gambling Task. Front. Psychol. 6, 1-9 (2015).

20. J. Duncan, M. Schramm, R. Thompson, I. Dumontheil, Task rules, working memory, and fluid intelligence. Psychon. Bull. Rev. 19, 864-870 (2012).

21. M. Pereg, N. Meiran, Rapid instructed task learning (but not automatic effects of instructions) is influenced by working memory load. PLoS One 14, 1-25 (2019).

22. R. W. Engle, J. J. Carullo, K. W. Collins, Individual Differences in Working Memory for Comprehension and Following Directions. J. Educ. Res. 84, 253-262 (1991).

23. A. Morris, F. Cushman, A common framework for theories of norm compliance. Soc. Philos. Policy 35, 101-127 (2018).

24. G. Andrighetto, R. Conte, Cognitive dynamics of norm compliance. From norm adoption to flexible automated conformity. Artif. Intell. Law 20, 359-381 (2012).

25. M. D. Harvey, M. E. Enzle, A cognitive model of social norms for understanding the transgressionhelping effect. J. Pers. Soc. Psychol. 41, 866-875 (1981).

26. R. B. Cialdini, N. J. Goldstein, Social Influence: Compliance and Conformity. Annu. Rev. Psychol. 55, 591-621 (2004). 
27. L. Stankov, The structure among measures of personality, social attitudes, values, and social norms. J. Individ. Differ. 28, 240-251 (2007).

28. E. Stamkou, et al., Cultural Collectivism and Tightness Moderate Responses to Norm Violators: Effects on Power Perception, Moral Emotions, and Leader Support. Personal. Soc. Psychol. Bull. 45, 947-964 (2019).

29. C. Feng, J. Cao, Y. Li, H. Wu, D. Mobbs, The pursuit of social acceptance: Aberrant conformity in social anxiety disorder. Soc. Cogn. Affect. Neurosci. 13, 809-817 (2018).

30. S.-S. Schreier, et al., Social anxiety and social norms in individualistic and collectivistic countries. Depress. Anxiety 27, 1128-1134 (2010).

31. C. A. Harper, L. P. Satchell, D. Fido, R. D. Latzman, Functional Fear Predicts Public Health Compliance in the COVID-19 Pandemic. Int. J. Ment. Health Addict. (2020)

32. C. Civai, I. Ma, The Enhancement of Social Norm Compliance: Prospects and Caveats. J. Cogn. Enhanc. 1, 26-30 (2017).

33. A. Gruszka, E. Nęcka, Limitations of working memory capacity: The cognitive and social consequences. Eur. Manag. J. 35, 776-784 (2017).

34. R. West, S. Michie, G. J. Rubin, R. Amlôt, Applying principles of behaviour change to reduce SARS-CoV-2 transmission. Nat. Hum. Behav. 4, 451-459 (2020).

35. C. C. Ruff, G. Ugazio, E. Fehr, Changing social norm compliance with noninvasive brain stimulation. Science (80-. ). 342, 482-484 (2013).

36. S. Kyllingsbæk, C. Bundesen, Changing change detection: Improving the reliability of measures of visual short-term memory capacity. Psychon. Bull. Rev. 16, 1000-1010 (2009).

37. W. Xie, et al., Affective bias in visual working memory is associated with capacity. Cogn. Emot., 116 (2016).

38. M. K. Johnson, et al., The relationship between working memory capacity and broad measures of cognitive ability in healthy adults and people with schizophrenia. Neuropsychology 27, 220-229 (2013).

39. N. Gannon, R. Ranzijn, Does emotional intelligence predict unique variance in life satisfaction beyond IQ and personality? Pers. Individ. Dif. 38, 1353-1364 (2005).

40. J. V. Olthuis, M. C. Watt, S. H. Stewart, Anxiety Sensitivity Index (ASI-3) subscales predict unique variance in anxiety and depressive symptoms. J. Anxiety Disord. 28, 115-124 (2014).

41. J. W. Zhang, R. T. Howell, Do time perspectives predict unique variance in life satisfaction beyond personality traits? Pers. Individ. Dif. 50, 1261-1266 (2011).

42. W. Xie, H. Li, Y. Zou, X. Sun, C. Shi, A suicidal mind tends to maintain less negative information in visual working memory. Psychiatry Res. 262, 549-557 (2018).

43. T. P. Moran, Anxiety and working memory capacity: A meta-analysis and narrative review. Psychol. Bull. 142, 831-864 (2016).

44. W. Xie, A. Berry, C. Lustig, P. Deldin, W. Zhang, Poor Sleep Quality and Compromised Visual Working Memory Capacity. J. Int. Neuropsychol. Soc. 25, 583-594 (2019).

45. D. P. MacKinnon, A. J. Fairchild, Current directions in mediation analysis. Curr. Dir. Psychol. Sci. 18, 16-20 (2009).

46. M. Spitzer, U. Fischbacher, B. Herrnberger, G. Grön, E. Fehr, The Neural Signature of Social Norm Compliance. Neuron 56, 185-196 (2007).

47. J. J. Van Bavel, et al., Using social and behavioural science to support COVID-19 pandemic response. Nat. Hum. Behav. 4, 460-471 (2020).

48. J. D. Murray, J. Jaramillo, X. J. Wang, Working memory and decision-making in a frontoparietal circuit model. J. Neurosci. 37, 12167-12186 (2017).

49. M. D’Esposito, B. R. Postle, The Cognitive Neuroscience of Working Memory. Annu. Rev. Psychol. 66, 115-142 (2015).

50. D. A. Moser, et al., An integrated brain-behavior model for working memory. Mol. Psychiatry 23, 1974-1980 (2018).

51. M. J. Kane, R. W. Engle, The role of prefrontal cortex in working-memory capacity, executive attention, and general fluid intelligence: An individual-differences perspective. Psychon. Bull. Rev. 9, 637-671 (2002).

52. J. M. Gold, et al., Reduced capacity but spared precision and maintenance of working memory representations in schizophrenia. Arch. Gen. Psychiatry 67, 570-577 (2010). 
53. Z. Shipstead, T. S. Redick, R. W. Engle, Is working memory training effective? Psychol. Bull. 138, 628-654 (2012).

54. T. Klingberg, Training and plasticity of working memory. Trends Cogn. Sci. 14, 317-324 (2010).

55. R. W. Engle, Working Memory Capacity as Executive Attention. Curr. Dir. Psychol. Sci. 11, 19-23 (2002).

56. E. K. Vogel, A. W. McCollough, M. G. Machizawa, Neural measures reveal individual differences in controlling access to working memory. Nature 438, 500-503 (2005).

57. R. L. Shrigley, Attitude and behavior are correlates. J. Res. Sci. Teach. 27, 97-113 (1990).

58. I. Ajzen, M. Fishbein, Attitude-behavior relations: A theoretical analysis and review of empirical research. Psychol. Bull. 84, 888-918 (1977).

59. M. Liu, L. Wronski, Trap questions in online surveys: Results from three web survey experiments. Int. J. Mark. Res. 60, 32-49 (2018).

60. M. D. Buhrmester, S. Talaifar, S. D. Gosling, An Evaluation of Amazon's Mechanical Turk, Its Rapid Rise, and Its Effective Use. Perspect. Psychol. Sci. 13, 149-154 (2018).

61. W. Xie, W. A. Bainbridge, S. Inati, C. I. Baker, K. A. Zaghloul, Memorability of words in arbitrary verbal associations modulates memory retrieval in the anterior temporal lobe. Nat. Hum. Behav. (2020).

62. M. S. Fritz, D. P. Mackinnon, Required Sample Size to Detect the Mediated Effect. 18, 233-239 (2007).

63. F. Faul, E. Erdfelder, A. Buchner, A.-G. Lang, Statistical power analyses using G*Power 3.1: Tests for correlation and regression analyses. Behav. Res. Methods 41, 1149-1160 (2009).

64. G. Stoet, PsyToolkit: A software package for programming psychological experiments using Linux. Behav. Res. Methods 42, 1096-1104 (2010).

65. G. Stoet, PsyToolkit: A Novel Web-Based Method for Running Online Questionnaires and Reaction-Time Experiments. Teach. Psychol. 44, 24-31 (2017).

66. W. Xie, et al., Schizotypy is associated with reduced mnemonic precision in visual working memory. Schizophr. Res. 193, 91-97 (2018).

67. K. Kroenke, R. L. Spitzer, D. Williams, The PHQ-9: Validity of a brief depression severity measure. J. Gen. Intern. Med. 16, 606-613 (2001).

68. R. L. Spitzer, K. Kroenke, J. B. W. Williams, B. Löwe, A brief measure for assessing generalized anxiety disorder: the GAD-7. Arch. Intern. Med. 166, 1092-1097 (2006).

69. D. J. Buysse, C. F. Reynolds, T. H. Monk, S. R. Berman, D. J. Kupfer, The Pittsburgh Sleep Quality Index: A new instrument for psychiatric practice and research. Psychiatry Res. 28, 193213 (1989).

70. F. Chiesi, M. Ciancaleoni, S. Galli, K. Morsanyi, C. Primi, Item Response Theory analysis and Differential Item Functioning across age, gender and country of a short form of the Advanced Progressive Matrices. Learn. Individ. Differ. 22, 390-396 (2012).

71. W. Arthur, D. V. Day, Development of a Short form for the Raven Advanced Progressive Matrices Test. Educ. Psychol. Meas. 54, 394-403 (1994).

72. J. Raven, J. C. Raven, J. H. Court, Manual for Raven's Progressive Matrices and Vocabulary Scales: Section 4. The Advanced Progressive Matrices (Harcourt Assessment, 1998).

73. A. R. A. Conway, N. Cowan, M. F. Bunting, D. J. Therriault, S. R. B. Minkoff, A latent variable analysis of working memory capacity, short-term memory capacity, processing speed, and general fluid intelligence. Intelligence 30, 163-183 (2002).

74. B. Rammstedt, O. P. John, Measuring personality in one minute or less: A 10-item short version of the Big Five Inventory in English and German. J. Res. Pers. 41, 203-212 (2007).

75. J. Williams, D. P. MacKinnon, Resampling and Distribution of the Product Methods for Testing Indirect Effects in Complex Models. Struct. Equ. Model. A Multidiscip. J. 15, 23-51 (2008). 


\section{Figure Legends}

Figure 1. Working memory (WM) change localization task and the relationship between WM capacity and social distancing. (A) Participants performed an online visual WM task, in which they tried to memorize a set of briefly presented color squares for $500 \mathrm{~ms}$ and after a 1000-ms delay tried to identify a changed color in the test display by clicking on it using a computer mouse. (B) Based on a median split of WM capacity across the subjects in each study, individuals with higher WM capacity tended to report more social distancing compliance, as compared with lower-capacity individuals. (C) The significant association between WM capacity and social distancing compliance is partly mediated by an individual's understanding of benefits over costs about social distancing. That is, participants with higher WM capacity may be able to better evaluate the true merits of social distancing and subsequently comply more with social distancing guidelines. This significant mediation effect has taken into account individual differences in age, gender, education, income level, depressed mood, anxious feeling, "big five" personality dimensions, and fluid intelligence as background confounders. Error bar areas in (B) indicate resampling standard error of the cumulative probability estimates.

Figure 2. A modified ultimatum game ( $A$ and $B$ ) for social norm compliance $(C)$ and its relationship to WM capacity (D). On each round, both players started with 25 money units (MUs). Player A also received an additional $100 \mathrm{MUs}$ and had to decide whether to transfer $\mathrm{x}$ amount of MUs, in steps of $10 \mathrm{MUs}$ from 0 to 100 , to another anonymous Player B to be fair. (A) In the baseline condition, Player B could only accept whatever MUs Player A offered, resulting in a reduction of Player A's earning by X MUs. (B) In the punishment condition, Player B could decide to either accept Player A's offer or punish Player A by taking Y MUs, ranging from 0 to 100 MUs, away from Player A. (C) The ultimate fairness for this game would be an even split of the 100 Mus between the two players (i.e., equality) in Western cultures. Therefore, the closer to equality the $\mathrm{X}$ amount of Mus Player A transferred to Player B is, the less likely Player B would punish Player A. Hence, over the course of the experiment, when faced with the punishment threat, Player A tended to transfer more MUs (close to the fairness norm of $50 \mathrm{MUs}$ ) to Player B, as compared to the baseline condition. The difference in the amount of MUs transferred from Player A to Player B is indicative of Player A's sanction-induced fairness norm compliance. (D) We found that this fairness norm compliance measure was significantly correlated with WM capacity in Study 2. Error bar areas in (C) indicate standard error of the mean estimates. And the solid line in (D) represent the linear fit of the data, with the dashed lines indicating its $95 \%$ confidence intervals. 
Study (500ms)

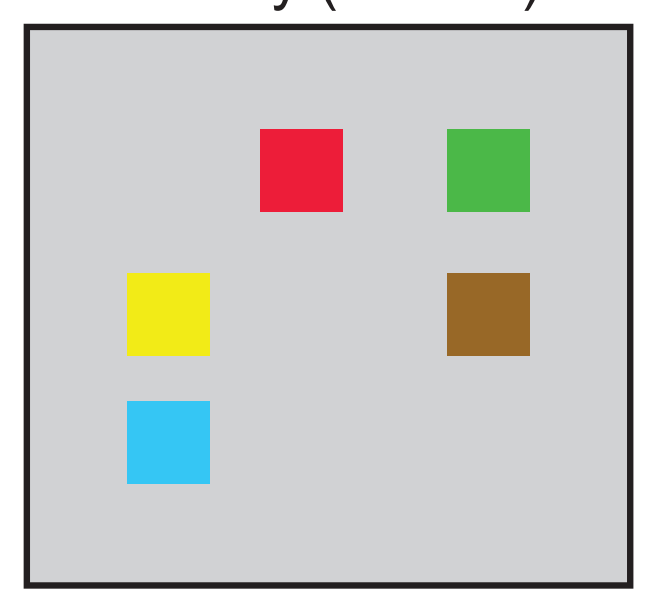

Delay $(1,000 \mathrm{~ms})$

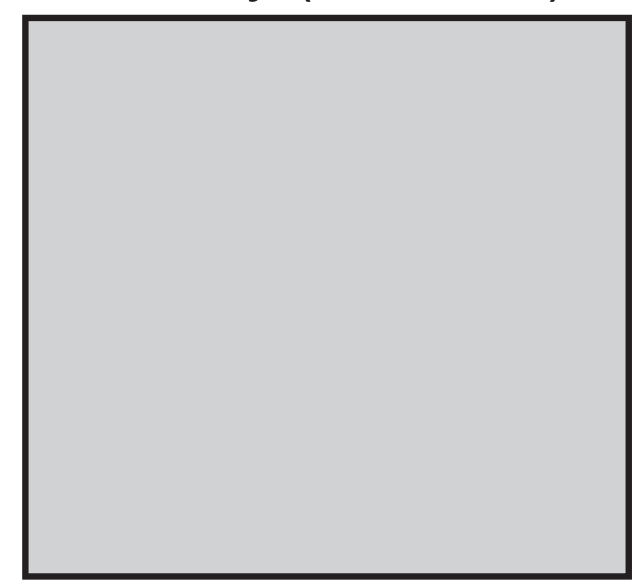

Test (until response)

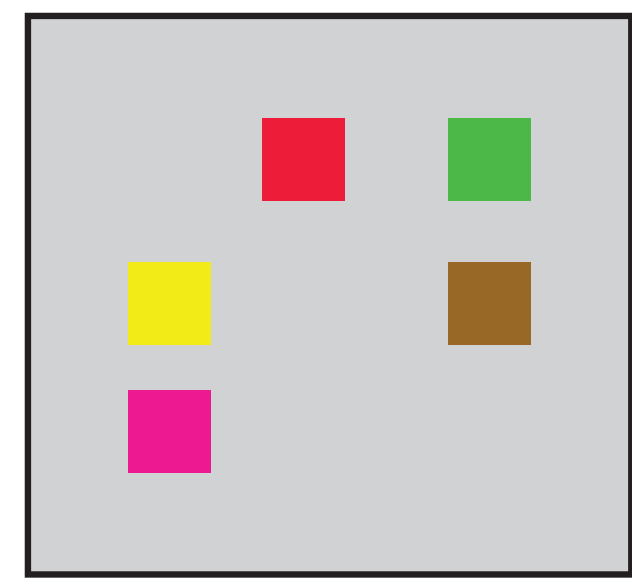

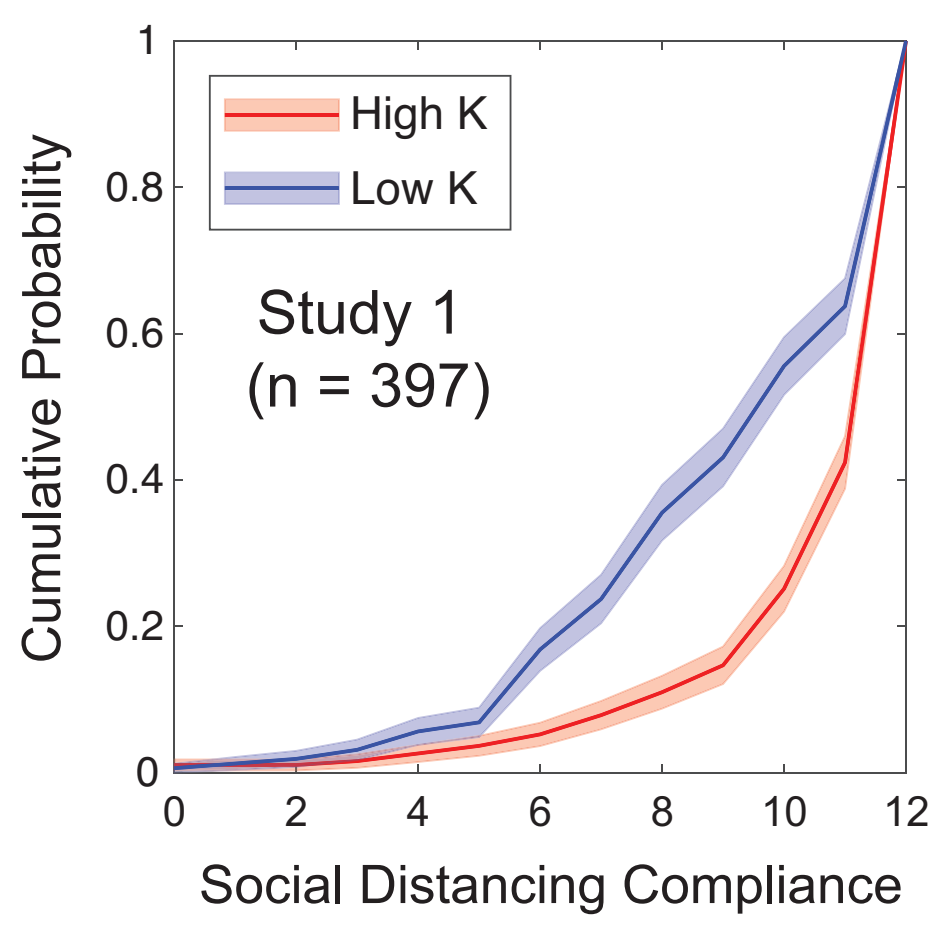

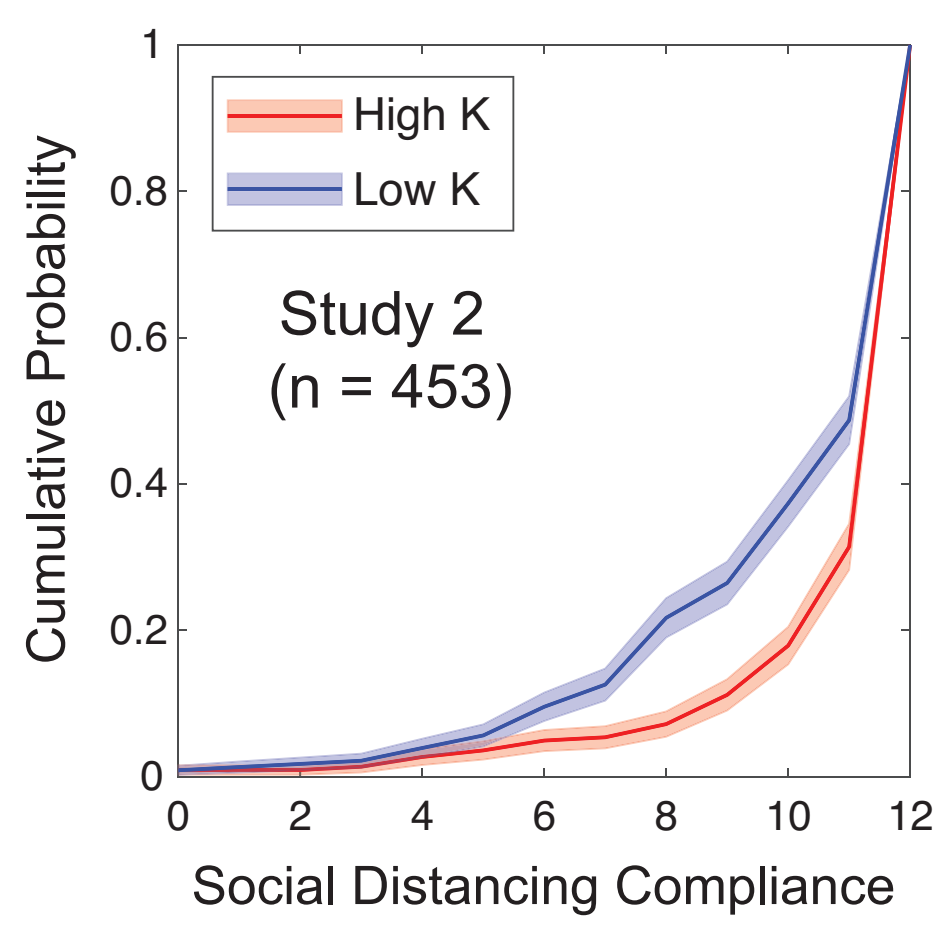

Weighting benefits over costs on social distancing

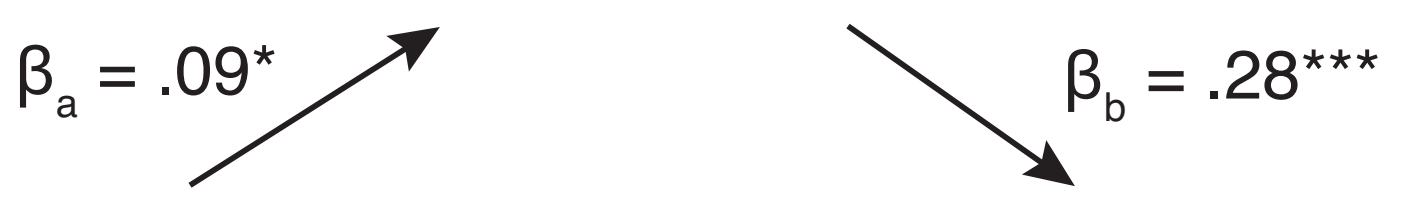

Working memory capacity (K)

$\beta_{c^{\prime}}=.12^{*}$

Social distancing compliance

Indirect effect: $\beta_{\mathrm{ab}}=.03[.003, .07], \mathrm{p}=.038$

(with confounder adjustment) 
Table 1. Predicting Social Distancing Compliance with Multiple Regression in Study 1

\begin{tabular}{|c|c|c|c|c|}
\hline & \multicolumn{2}{|l|}{ Model 1} & \multicolumn{2}{|l|}{ Model 2} \\
\hline & $\beta[95 \% \mathrm{Cl}]$ & $p$ & $\beta[95 \% \mathrm{Cl}]$ & $p$ \\
\hline Age & $.12[.03, .22]$ & .011 & $.15[.05, .24]$ & .002 \\
\hline Gender & $-.15[-.24,-.06]$ & .001 & $-.14[-.23,-.05]$ & .003 \\
\hline Education & $.03[-.07, .13]$ & .55 & $.04[-.06, .13]$ & .44 \\
\hline Income & $.01[-.09, .10]$ & .86 & $-.01[-.10, .09]$ & .92 \\
\hline Depressed mood & $-.44[-.63 .-.26]$ & $<.001$ & $-.35[-.54,-.16]$ & $<.001$ \\
\hline Anxious feeling & $.18[.003, .35]$ & .047 & $.15[-.02, .33]$ & .09 \\
\hline Sleep quality & $-.08[-.20, .04]$ & .19 & $-.08[-.20, .04]$ & .20 \\
\hline WM Capacity & & & $.18[.09, .28]$ & $<.001$ \\
\hline $\mathrm{R}^{2}\left(\mathrm{R}^{2}\right.$ adjusted $)$ & $.18(.17)$ & & $.21(.20)$ & \\
\hline Comparison & \multicolumn{4}{|c|}{$\Delta \mathrm{R}^{2}=.03, F_{(1,388)}=13.57, p<.001$} \\
\hline
\end{tabular}


Table 2. Predicting Social Distancing Compliance with Multiple Regression in Study 2

\begin{tabular}{|c|c|c|c|c|}
\hline & \multicolumn{2}{|l|}{ Model 1} & \multicolumn{2}{|l|}{ Model 2} \\
\hline & $\beta[95 \% \mathrm{Cl}]$ & $P$ & $\beta[95 \% \mathrm{Cl}]$ & $p$ \\
\hline Age & $.12[.04, .21]$ & .005 & $.15[.06, .23]$ & $<.001$ \\
\hline Gender & $-.10[-.18,-.01]$ & .018 & $-.10[-.18,-.01]$ & .022 \\
\hline Education & $-.09[-.18, .001]$ & .052 & $-.08[-.17, .01]$ & .068 \\
\hline Income & $.05[-.04, .14]$ & .30 & $.05[-.04, .14]$ & .26 \\
\hline Depressed mood & $-.25[-.41,-.09]$ & .002 & $-.23[-.38,-.07]$ & .005 \\
\hline Anxious feeling & $.16[.01, .32]$ & .042 & $.17[.02, .32]$ & .031 \\
\hline Agreeableness & $.18[.08, .27]$ & $<.001$ & $.18[.08, .27]$ & $<.001$ \\
\hline Conscientiousness & $.04[-.06, .15]$ & .44 & $.04[-.07, .14]$ & .50 \\
\hline Extraversion & $-.06[-.15, .03]$ & .18 & $-.05[-.14, .04]$ & .27 \\
\hline Openness & $.14[.05, .24]$ & .002 & $.13[.04, .22]$ & .006 \\
\hline Neuroticism & $.07[-.05, .18]$ & .25 & $.06[-.05, .17]$ & .25 \\
\hline RAPM & $.13[.05, .22]$ & .003 & $.09[-.01, .18]$ & .063 \\
\hline WM Capacity & & & $.14[.05, .24]$ & .004 \\
\hline $\mathrm{R}^{2}\left(\mathrm{R}^{2}\right.$ adjusted $)$ & $.20(.19)$ & & $.22(.20)$ & \\
\hline Comparison & $\Delta R^{2}=$ & $2, F_{(1,43}$ & $3.50, p=.004$ & \\
\hline
\end{tabular}

Note: RAPM = Raven's Advanced Progressive Matrices. 


\section{Supplementary Information}

Example "Trap Question"

Which of the following is not a US city? This is a data quality check. Regardless of the true value, please select Chicago.

- New York City

- Tokyo

- Chicago

- Boston

- Miami

Supplementary Table S1. Demographic Details of Included Participants in Study 1 and Study 2.

\begin{tabular}{|c|c|c|c|c|}
\hline & \multicolumn{2}{|c|}{ Study 1} & \multicolumn{2}{|c|}{ Study 2} \\
\hline & Frequency & $\%$ & Frequency & $\%$ \\
\hline \multicolumn{5}{|l|}{ Gender } \\
\hline Female & 198 & 49.9 & 212 & 46.8 \\
\hline Male & 199 & 50.1 & 241 & 53.2 \\
\hline \multicolumn{5}{|l|}{ Education level } \\
\hline Primary school & 0 & 0.0 & 0 & 0.0 \\
\hline Middle school or equivalent & 0 & 0.0 & 2 & 0.4 \\
\hline High school or equivalent & 85 & 21.4 & 122 & 26.9 \\
\hline Undergraduate degree & 212 & 53.4 & 250 & 55.2 \\
\hline Master degree & 83 & 20.9 & 71 & 15.7 \\
\hline Doctoral degree & 17 & 4.3 & 8 & 1.8 \\
\hline \multicolumn{5}{|l|}{ Income level ("for my age group ...") } \\
\hline below average income in my country & 129 & 32.5 & 162 & 35.8 \\
\hline average income in my country & 228 & 57.4 & 247 & 54.5 \\
\hline above average income in my country & 40 & 10.1 & 44 & 9.7 \\
\hline \multicolumn{5}{|l|}{ Ethnicity } \\
\hline Hispanic & 36 & 9.1 & 28 & 6.2 \\
\hline White (non-Hispanic) & 301 & 75.8 & 315 & 69.5 \\
\hline Asian (South or Southeast) & 29 & 7.3 & 73 & 16.1 \\
\hline Asian (East) & 13 & 3.3 & 17 & 3.8 \\
\hline Black & 14 & 3.5 & 13 & 2.9 \\
\hline Pacific Islander & 0 & 0.0 & 0 & 0.0 \\
\hline Other & 4 & 1.0 & 7 & 1.5 \\
\hline Total & 397 & & 453 & \\
\hline
\end{tabular}


Supplementary Table S2. Correlation Matrix of Variables of Interest in Study 1

\begin{tabular}{|c|c|c|c|c|c|c|c|c|}
\hline & 1 & 2 & 3 & 4 & 5 & 6 & 7 & 8 \\
\hline $\begin{array}{l}\text { 1. Social distancing } \\
\text { compliance }\end{array}$ & - & & & & & & & \\
\hline 2. Age & $.21^{* * *}$ & - & & & & & & \\
\hline 3. Gender & $-.15^{\star *}$ & -.05 & - & & & & & \\
\hline 4. Education & -.06 & $-.12^{*}$ & .03 & - & & & & \\
\hline 5. Income & .02 & -.01 & $.15^{\star *}$ & $.23^{* * *}$ & - & & & \\
\hline 6. Depressed mood & $-.37^{* * *}$ & $-.27^{* * *}$ & -.02 & $.23^{* \star *}$ & -.09 & - & & \\
\hline 7. Anxious feelings & $-.27^{* * *}$ & $-.28^{* * *}$ & -.07 & $.20^{* \star *}$ & $-.10^{*}$ & $.85^{\star * *}$ & - & \\
\hline 8. Sleep quality & $-.27^{* * *}$ & $-.13^{* *}$ & -.08 & .09 & -.06 & $.66^{\star \star *}$ & $.60^{\star \star *}$ & - \\
\hline 9. WM capacity & $.29^{\star * *}$ & -.04 & -.07 & $-.10^{*}$ & .08 & $-.37^{* * *}$ & $-.26^{* \star *}$ & $-.24^{* * *}$ \\
\hline
\end{tabular}

Note: $n=397, \mathrm{WM}=$ working memory, ${ }^{*} p<.05,{ }^{* *} p<.01,{ }^{* * *} p<.001$. 
Supplementary Table S3. Correlation Matrix of Variables of Interest in Study 2

\begin{tabular}{|c|c|c|c|c|c|c|c|c|c|c|c|c|c|}
\hline & 1 & 2 & 3 & 4 & 5 & 6 & 7 & 8 & 9 & 10 & 11 & 12 & 13 \\
\hline $\begin{array}{l}\text { 1. Social distancing } \\
\text { compliance }\end{array}$ & - & & & & & & & & & & & & \\
\hline 2. Age & $.18^{* * *}$ & - & & & & & & & & & & & \\
\hline 3. Gender & $-.13^{\star *}$ & $-.13^{\star \star}$ & - & & & & & & & & & & \\
\hline 4. Education & $-.13^{* *}$ & -.01 & .05 & - & & & & & & & & & \\
\hline 5. Income & .04 & -.03 & .04 & $.20^{\star * *}$ & - & & & & & & & & \\
\hline 6. Depressed mood & $-.28^{* * *}$ & $-.16^{* * *}$ & .03 & $.16^{* * *}$ & $-.12^{*}$ & - & & & & & & & \\
\hline 7. Anxious feelings & $-.17^{* * *}$ & $-.12^{*}$ & .02 & $.17^{\star * *}$ & -.07 & $.81^{\star \star *}$ & - & & & & & & \\
\hline 8. Agreeableness & $.23^{\star * \star}$ & .08 & .03 & .01 & $.13^{* *}$ & $-.34^{* \star *}$ & $-.35^{\star \star \star}$ & - & & & & & \\
\hline 9. Conscientiousness & $.24^{* * *}$ & $.14^{* *}$ & -.08 & -.07 & $.18^{* * *}$ & $-.51^{* * *}$ & $-.42^{* * *}$ & $.41^{* * *}$ & - & & & & \\
\hline 10. Extraversion & -.05 & .02 & .002 & .05 & $.18^{* * *}$ & -.06 & $-.10^{*}$ & $.15^{\star}$ & .09 & - & & & \\
\hline 11. Openness & $.25^{\star * *}$ & .04 & .003 & $-.13^{* *}$ & -.04 & $-.30^{* * *}$ & $-.22^{* * *}$ & $.23^{* * *}$ & $.30^{* * *}$ & $.12^{*}$ & - & & \\
\hline 12. Neuroticism & -.05 & $-.09^{*}$ & $-.10^{*}$ & .03 & $-.20^{\star \star *}$ & $.41^{* * *}$ & $.51^{* \star *}$ & $-.40^{\star * *}$ & $-.39^{\star * *}$ & $-.34^{\star * *}$ & $-.17^{* * *}$ & - & \\
\hline 13. Fluid intelligence & $.21^{\star \star \star}$ & .07 & -.02 & $-.11^{*}$ & .02 & $-.19^{* \star *}$ & $-.12^{* *}$ & -.001 & .09 & $-.13^{\star * *}$ & $.12^{*}$ & .03 & - \\
\hline 14. WM capacity & $.25^{\star \star \star}$ & -.09 & -.03 & $-.14^{* *}$ & -.01 & $-.31^{* * *}$ & $-.26^{\star * *}$ & .09 & $.18^{* * *}$ & $-.10^{*}$ & $.21^{* \star \star}$ & -.07 & $.39^{\star \star \star}$ \\
\hline
\end{tabular}

Note: $n=453$, WM $=$ working memory, ${ }^{*} p<.05,{ }^{* *} p<.01,{ }^{* * *} p<.001$. 
Supplementary Table S4. Statements of Benefits and Costs about Social Distancing and Principle Component Analysis of the Self-report Rating on How Much Participants Think a Statement is True.

\begin{tabular}{|c|c|c|c|c|}
\hline Category & Statement & Note & \multicolumn{2}{|c|}{$\begin{array}{l}\text { Component } \\
\text { Loadings }\end{array}$} \\
\hline Benefit & $\begin{array}{l}\text { Social distancing can prevent } \\
\text { me from catching coronavirus. }\end{array}$ & Self-related interest & .79 & - \\
\hline $\begin{array}{l}\text { Benefit } \\
\text { (Reverse } \\
\text { coded) }\end{array}$ & $\begin{array}{l}\text { Young adults do not need to } \\
\text { practice social distancing. }\end{array}$ & $\begin{array}{l}\text { Social distancing among young adults } \\
\text { is beneficial not only to stop virus from } \\
\text { spreading, but also to free up medical } \\
\text { resource. }\end{array}$ & .55 & - \\
\hline Benefit & $\begin{array}{l}\text { Social distancing stops } \\
\text { coronavirus from spreading } \\
\text { around. }\end{array}$ & General benefit & .74 & - \\
\hline Benefit & $\begin{array}{l}\text { Older adults should stay at } \\
\text { home because they are more } \\
\text { vulnerable. }\end{array}$ & Benefit for vulnerable populations & .74 & - \\
\hline Benefit & $\begin{array}{l}\text { Social distancing may minimize } \\
\text { the burden on medical } \\
\text { resources, so people in need } \\
\text { can use them. }\end{array}$ & Societal benefit & .73 & - \\
\hline Cost & $\begin{array}{l}\text { Not being able to hang out } \\
\text { makes me upset. }\end{array}$ & Self-related cost & - & .64 \\
\hline Cost & $\begin{array}{l}\text { Small business (e.g., local } \\
\text { restaurants and bars) could not } \\
\text { survive if people keep social } \\
\text { distancing. }\end{array}$ & Societal cost & - & .67 \\
\hline Cost & $\begin{array}{l}\text { Social distancing makes people } \\
\text { lose their jobs. }\end{array}$ & Financial cost & - & .67 \\
\hline Cost & $\begin{array}{l}\text { I practice social distancing } \\
\text { because people around me do } \\
\text { so. }\end{array}$ & $\begin{array}{l}\text { Social cost of not following others. A } \\
\text { higher score of this social approval } \\
\text { item indicates a higher sensitivity to } \\
\text { social cost }\end{array}$ & - & .53 \\
\hline
\end{tabular}

Note: Prompt: "There are a lot of opinions about the benefit of social distancing. Please tell us what you think (from 'Don't think it is true' = 0 to 'It is very true' $=3$ )." Applied rotation method is varimax. Only component loadings greater than 0.45 are shown in the table. 
Supplementary Table S5. Average Payoff Structure of the Fairness Norm Decision Making Task.

\begin{tabular}{ccc}
\hline $\begin{array}{c}\text { Player A's transfer to } \\
\text { Player B (X) }\end{array}$ & $\begin{array}{c}\text { Player A's average total } \\
\text { payoff in the baseline } \\
\text { condition }\end{array}$ & $\begin{array}{c}\text { Player A's average total } \\
\text { payoff in the punishment } \\
\text { condition }\end{array}$ \\
\hline 0 & 125 & 8.25 \\
10 & 115 & 25 \\
20 & 105 & 15.05 \\
30 & 95 & 19.25 \\
40 & 85 & 40.75 \\
50 & 75 & 53.35 \\
60 & 65 & 65 \\
70 & 55 & 55 \\
80 & 45 & 45 \\
90 & 35 & 35 \\
100 & 25 & 25 \\
\hline
\end{tabular}


Supplementary Table S6. Predicting Fairness Norm Compliance with Multiple Regression in Study 2

\begin{tabular}{rcccr}
\hline & \multicolumn{2}{c}{ Model 1 } & \multicolumn{1}{c}{ Model 2} \\
\cline { 2 - 5 } Age & $-.04[-.12, .05]$ & .38 & $-.02[-.11, .07]$ & .61 \\
Gender & $.03[-.06, .11]$ & .55 & $.03[-.06, .11]$ & .50 \\
Education & $-.08[-.17, .01]$ & .073 & $-.08[-.17, .01]$ & .09 \\
Income & $-.05[-.14, .04]$ & .25 & $-.05[-.14, .04]$ & .27 \\
Depressed mood & $-.05[-.21, .11]$ & .53 & $-.03[-.19, .12]$ & .69 \\
Anxious feeling & $-.10[-.26, .06]$ & .21 & $-.10[-.26, .06]$ & .23 \\
Agreeableness & $-.08[-.18, .02]$ & .13 & $-.08[-.18, .02]$ & .13 \\
Conscientiousness & $.13[.03, .24]$ & .015 & $.13[.02, .24]$ & .018 \\
Extraversion & $-.01[-.11, .08]$ & .79 & $-.01[-.10, .09]$ & .92 \\
Openness & $-.04[-.13, .06]$ & .45 & $-.05[-.14, .05]$ & .33 \\
Neuroticism & $-.04[-.15, .08]$ & .51 & $-.04[-.15, .07]$ & .51 \\
RAPM & $.29[.20, .38]$ & $<.001$ & $.26[.16, .35]$ & $<.001$ \\
WM Capacity & & & $.10[.003, .20]$ & .043 \\
\hline $\mathrm{R}^{2}\left(\mathrm{R}^{2}\right.$ adjusted) & $.17(.15)$ & & $.18(.15)$ & \\
Comparison & $\Delta \mathrm{R}^{2}=.01, F_{(1,439)}=4.13, p=.043$ & \\
\hline
\end{tabular}

Note: RAPM = Raven's Advanced Progressive Matrices. 


\section{Supplementary Information}

Example "Trap Question"

Which of the following is not a US city? This is a data quality check. Regardless of the true value, please select Chicago.

- New York City

- Tokyo

- Chicago

- Boston

- Miami

Supplementary Table S1. Demographic Details of Included Participants in Study 1 and Study 2.

\begin{tabular}{|c|c|c|c|c|}
\hline & \multicolumn{2}{|c|}{ Study 1} & \multicolumn{2}{|c|}{ Study 2} \\
\hline & Frequency & $\%$ & Frequency & $\%$ \\
\hline \multicolumn{5}{|l|}{ Gender } \\
\hline Female & 198 & 49.9 & 212 & 46.8 \\
\hline Male & 199 & 50.1 & 241 & 53.2 \\
\hline \multicolumn{5}{|l|}{ Education level } \\
\hline Primary school & 0 & 0.0 & 0 & 0.0 \\
\hline Middle school or equivalent & 0 & 0.0 & 2 & 0.4 \\
\hline High school or equivalent & 85 & 21.4 & 122 & 26.9 \\
\hline Undergraduate degree & 212 & 53.4 & 250 & 55.2 \\
\hline Master degree & 83 & 20.9 & 71 & 15.7 \\
\hline Doctoral degree & 17 & 4.3 & 8 & 1.8 \\
\hline \multicolumn{5}{|l|}{ Income level ("for my age group ...") } \\
\hline below average income in my country & 129 & 32.5 & 162 & 35.8 \\
\hline average income in my country & 228 & 57.4 & 247 & 54.5 \\
\hline above average income in my country & 40 & 10.1 & 44 & 9.7 \\
\hline \multicolumn{5}{|l|}{ Ethnicity } \\
\hline Hispanic & 36 & 9.1 & 28 & 6.2 \\
\hline White (non-Hispanic) & 301 & 75.8 & 315 & 69.5 \\
\hline Asian (South or Southeast) & 29 & 7.3 & 73 & 16.1 \\
\hline Asian (East) & 13 & 3.3 & 17 & 3.8 \\
\hline Black & 14 & 3.5 & 13 & 2.9 \\
\hline Pacific Islander & 0 & 0.0 & 0 & 0.0 \\
\hline Other & 4 & 1.0 & 7 & 1.5 \\
\hline Total & 397 & & 453 & \\
\hline
\end{tabular}


Supplementary Table S2. Correlation Matrix of Variables of Interest in Study 1

\begin{tabular}{|c|c|c|c|c|c|c|c|c|}
\hline & 1 & 2 & 3 & 4 & 5 & 6 & 7 & 8 \\
\hline $\begin{array}{l}\text { 1. Social distancing } \\
\text { compliance }\end{array}$ & - & & & & & & & \\
\hline 2. Age & $.21^{* * *}$ & - & & & & & & \\
\hline 3. Gender & $-.15^{\star *}$ & -.05 & - & & & & & \\
\hline 4. Education & -.06 & $-.12^{*}$ & .03 & - & & & & \\
\hline 5. Income & .02 & -.01 & $.15^{\star *}$ & $.23^{* * *}$ & - & & & \\
\hline 6. Depressed mood & $-.37^{* * *}$ & $-.27^{* * *}$ & -.02 & $.23^{* \star *}$ & -.09 & - & & \\
\hline 7. Anxious feelings & $-.27^{* * *}$ & $-.28^{* * *}$ & -.07 & $.20^{* \star *}$ & $-.10^{*}$ & $.85^{\star * *}$ & - & \\
\hline 8. Sleep quality & $-.27^{* * *}$ & $-.13^{* *}$ & -.08 & .09 & -.06 & $.66^{\star \star *}$ & $.60^{\star \star *}$ & - \\
\hline 9. WM capacity & $.29^{\star * *}$ & -.04 & -.07 & $-.10^{*}$ & .08 & $-.37^{* * *}$ & $-.26^{* \star *}$ & $-.24^{* * *}$ \\
\hline
\end{tabular}

Note: $n=397, \mathrm{WM}=$ working memory, ${ }^{*} p<.05,{ }^{* *} p<.01,{ }^{* * *} p<.001$. 
Supplementary Table S3. Correlation Matrix of Variables of Interest in Study 2

\begin{tabular}{|c|c|c|c|c|c|c|c|c|c|c|c|c|c|}
\hline & 1 & 2 & 3 & 4 & 5 & 6 & 7 & 8 & 9 & 10 & 11 & 12 & 13 \\
\hline $\begin{array}{l}\text { 1. Social distancing } \\
\text { compliance }\end{array}$ & - & & & & & & & & & & & & \\
\hline 2. Age & $.18^{* * *}$ & - & & & & & & & & & & & \\
\hline 3. Gender & $-.13^{\star *}$ & $-.13^{\star \star}$ & - & & & & & & & & & & \\
\hline 4. Education & $-.13^{* *}$ & -.01 & .05 & - & & & & & & & & & \\
\hline 5. Income & .04 & -.03 & .04 & $.20^{\star * *}$ & - & & & & & & & & \\
\hline 6. Depressed mood & $-.28^{* * *}$ & $-.16^{* * *}$ & .03 & $.16^{* * *}$ & $-.12^{*}$ & - & & & & & & & \\
\hline 7. Anxious feelings & $-.17^{* * *}$ & $-.12^{*}$ & .02 & $.17^{\star * *}$ & -.07 & $.81^{\star \star *}$ & - & & & & & & \\
\hline 8. Agreeableness & $.23^{\star * \star}$ & .08 & .03 & .01 & $.13^{* *}$ & $-.34^{* \star *}$ & $-.35^{\star \star \star}$ & - & & & & & \\
\hline 9. Conscientiousness & $.24^{* * *}$ & $.14^{* *}$ & -.08 & -.07 & $.18^{* * *}$ & $-.51^{* * *}$ & $-.42^{* * *}$ & $.41^{* * *}$ & - & & & & \\
\hline 10. Extraversion & -.05 & .02 & .002 & .05 & $.18^{* * *}$ & -.06 & $-.10^{*}$ & $.15^{\star}$ & .09 & - & & & \\
\hline 11. Openness & $.25^{\star * *}$ & .04 & .003 & $-.13^{* *}$ & -.04 & $-.30^{* * *}$ & $-.22^{* * *}$ & $.23^{* * *}$ & $.30^{* * *}$ & $.12^{*}$ & - & & \\
\hline 12. Neuroticism & -.05 & $-.09^{*}$ & $-.10^{*}$ & .03 & $-.20^{\star \star *}$ & $.41^{* * *}$ & $.51^{* \star *}$ & $-.40^{\star * *}$ & $-.39^{\star * *}$ & $-.34^{\star * *}$ & $-.17^{* * *}$ & - & \\
\hline 13. Fluid intelligence & $.21^{\star \star \star}$ & .07 & -.02 & $-.11^{*}$ & .02 & $-.19^{* \star *}$ & $-.12^{* *}$ & -.001 & .09 & $-.13^{\star * *}$ & $.12^{*}$ & .03 & - \\
\hline 14. WM capacity & $.25^{\star \star \star}$ & -.09 & -.03 & $-.14^{* *}$ & -.01 & $-.31^{* * *}$ & $-.26^{\star * *}$ & .09 & $.18^{* * *}$ & $-.10^{*}$ & $.21^{* \star \star}$ & -.07 & $.39^{\star \star \star}$ \\
\hline
\end{tabular}

Note: $n=453$, WM $=$ working memory, ${ }^{*} p<.05,{ }^{* *} p<.01,{ }^{* * *} p<.001$. 
Supplementary Table S4. Statements of Benefits and Costs about Social Distancing and Principle Component Analysis of the Self-report Rating on How Much Participants Think a Statement is True.

\begin{tabular}{|c|c|c|c|c|}
\hline Category & Statement & Note & \multicolumn{2}{|c|}{$\begin{array}{l}\text { Component } \\
\text { Loadings }\end{array}$} \\
\hline Benefit & $\begin{array}{l}\text { Social distancing can prevent } \\
\text { me from catching coronavirus. }\end{array}$ & Self-related interest & .79 & - \\
\hline $\begin{array}{l}\text { Benefit } \\
\text { (Reverse } \\
\text { coded) }\end{array}$ & $\begin{array}{l}\text { Young adults do not need to } \\
\text { practice social distancing. }\end{array}$ & $\begin{array}{l}\text { Social distancing among young adults } \\
\text { is beneficial not only to stop virus from } \\
\text { spreading, but also to free up medical } \\
\text { resource. }\end{array}$ & .55 & - \\
\hline Benefit & $\begin{array}{l}\text { Social distancing stops } \\
\text { coronavirus from spreading } \\
\text { around. }\end{array}$ & General benefit & .74 & - \\
\hline Benefit & $\begin{array}{l}\text { Older adults should stay at } \\
\text { home because they are more } \\
\text { vulnerable. }\end{array}$ & Benefit for vulnerable populations & .74 & - \\
\hline Benefit & $\begin{array}{l}\text { Social distancing may minimize } \\
\text { the burden on medical } \\
\text { resources, so people in need } \\
\text { can use them. }\end{array}$ & Societal benefit & .73 & - \\
\hline Cost & $\begin{array}{l}\text { Not being able to hang out } \\
\text { makes me upset. }\end{array}$ & Self-related cost & - & .64 \\
\hline Cost & $\begin{array}{l}\text { Small business (e.g., local } \\
\text { restaurants and bars) could not } \\
\text { survive if people keep social } \\
\text { distancing. }\end{array}$ & Societal cost & - & .67 \\
\hline Cost & $\begin{array}{l}\text { Social distancing makes people } \\
\text { lose their jobs. }\end{array}$ & Financial cost & - & .67 \\
\hline Cost & $\begin{array}{l}\text { I practice social distancing } \\
\text { because people around me do } \\
\text { so. }\end{array}$ & $\begin{array}{l}\text { Social cost of not following others. A } \\
\text { higher score of this social approval } \\
\text { item indicates a higher sensitivity to } \\
\text { social cost }\end{array}$ & - & .53 \\
\hline
\end{tabular}

Note: Prompt: "There are a lot of opinions about the benefit of social distancing. Please tell us what you think (from 'Don't think it is true' = 0 to 'It is very true' $=3$ )." Applied rotation method is varimax. Only component loadings greater than 0.45 are shown in the table. 
Supplementary Table S5. Average Payoff Structure of the Fairness Norm Decision Making Task.

\begin{tabular}{ccc}
\hline $\begin{array}{c}\text { Player A's transfer to } \\
\text { Player B (X) }\end{array}$ & $\begin{array}{c}\text { Player A's average total } \\
\text { payoff in the baseline } \\
\text { condition }\end{array}$ & $\begin{array}{c}\text { Player A's average total } \\
\text { payoff in the punishment } \\
\text { condition }\end{array}$ \\
\hline 0 & 125 & 8.25 \\
10 & 115 & 25 \\
20 & 105 & 15.05 \\
30 & 95 & 19.25 \\
40 & 85 & 40.75 \\
50 & 75 & 53.35 \\
60 & 65 & 65 \\
70 & 55 & 55 \\
80 & 45 & 45 \\
90 & 35 & 35 \\
100 & 25 & 25 \\
\hline
\end{tabular}


Supplementary Table S6. Predicting Fairness Norm Compliance with Multiple Regression in Study 2

\begin{tabular}{rcccr}
\hline & \multicolumn{2}{c}{ Model 1 } & \multicolumn{1}{c}{ Model 2} \\
\cline { 2 - 5 } Age & $-.04[-.12, .05]$ & .38 & $-.02[-.11, .07]$ & .61 \\
Gender & $.03[-.06, .11]$ & .55 & $.03[-.06, .11]$ & .50 \\
Education & $-.08[-.17, .01]$ & .073 & $-.08[-.17, .01]$ & .09 \\
Income & $-.05[-.14, .04]$ & .25 & $-.05[-.14, .04]$ & .27 \\
Depressed mood & $-.05[-.21, .11]$ & .53 & $-.03[-.19, .12]$ & .69 \\
Anxious feeling & $-.10[-.26, .06]$ & .21 & $-.10[-.26, .06]$ & .23 \\
Agreeableness & $-.08[-.18, .02]$ & .13 & $-.08[-.18, .02]$ & .13 \\
Conscientiousness & $.13[.03, .24]$ & .015 & $.13[.02, .24]$ & .018 \\
Extraversion & $-.01[-.11, .08]$ & .79 & $-.01[-.10, .09]$ & .92 \\
Openness & $-.04[-.13, .06]$ & .45 & $-.05[-.14, .05]$ & .33 \\
Neuroticism & $-.04[-.15, .08]$ & .51 & $-.04[-.15, .07]$ & .51 \\
RAPM & $.29[.20, .38]$ & $<.001$ & $.26[.16, .35]$ & $<.001$ \\
WM Capacity & & & $.10[.003, .20]$ & .043 \\
\hline $\mathrm{R}^{2}\left(\mathrm{R}^{2}\right.$ adjusted) & $.17(.15)$ & & $.18(.15)$ & \\
Comparison & $\Delta \mathrm{R}^{2}=.01, F_{(1,439)}=4.13, p=.043$ & \\
\hline
\end{tabular}

Note: RAPM = Raven's Advanced Progressive Matrices. 